Article

\title{
Synthesis of Lignin-Based MMA-co-BA Hybrid Resins from Cornstalk Residue via RAFT Miniemulsion Polymerization and Their Characteristics
}

\author{
Yuzhi Xu ${ }^{1,2,3, *}$, Ning $\operatorname{Li}^{1}$, Guangbin Wang ${ }^{1}$, Chunpeng Wang ${ }^{1,2,3, *}$ and Fuxiang Chu ${ }^{1,2,3, *}$ \\ 1 Institute of Chemical Industry of Forest Products, Chinese Academy of Forestry, Nanjing 210042, China; \\ lining20140214@163.com (N.L.); wanggb_robin@163.com (G.W.) \\ 2 Research Institute of Forestry New Technology, Chinese Academy of Forestry, Beijing 100091, China \\ 3 Co-Innovation Center of Efficient Processing and Utilization of Forest Resources, Jiangsu Province, \\ Nanjing Forestry University, Nanjing 210037, China \\ * Correspondence: xuyuzhi@icifp.cn (Y.X.); wangchunpeng@icifp.cn (C.W.); chufuxiang@caf.ac.cn (F.C.); \\ Tel.: +86-8548-2475 (Y.X.)
}

check for

updates

Citation: $\mathrm{Xu}, \mathrm{Y}$.; Li, N.; Wang, G.; Wang, C.; Chu, F. Synthesis of Lignin-Based MMA-co-BA Hybrid Resins from Cornstalk Residue via RAFT Miniemulsion Polymerization and Their Characteristics. Polymers 2021, 13, 968. https://doi.org/ $10.3390 /$ polym 13060968

Academic Editor: Antonios N. Papadopoulos

Received: 8 February 2021

Accepted: 17 March 2021

Published: 22 March 2021

Publisher's Note: MDPI stays neutral with regard to jurisdictional claims in published maps and institutional affiliations.

Copyright: (c) 2021 by the authors. Licensee MDPI, Basel, Switzerland. This article is an open access article distributed under the terms and conditions of the Creative Commons Attribution (CC BY) license (https:// creativecommons.org/licenses/by/ $4.0 /)$
Abstract: The conversion of cornstalk lignin derived from the co-product of bio-refinery into valueadded products such as polymeric material has remarkable environmental and economic potential. A novel bio-based methyl methacrylate copolymerized with butyl acrylate (MMA-co-BA) hybrid resin in our research was prepared by the reversible addition-fragmentation chain transfer method using lignin-graft-polyacrylamide (lignin-g-PAM) as a bio-derived macromolecular chain transfer agent. The molecular architecture of lignin-g-PAM and the lignin-based MMA-co-BA hybrid resin was elucidated using ${ }^{1} \mathrm{H}$ nuclear magnetic resonance and attenuated total reflectance-Fourier transform infrared. The thermal behavior and mechanical performance of the resultant lignin-based MMA-co-BA hybrid resins were also investigated through thermogravimetric analysis, differential scanning calorimetry, and a stress-strain test, respectively. The lignin-based acrylate resins system exhibited structure-related thermal and mechanical properties. Compared with pure MMA-co-BA resin, the incorporation of lignin into various lignin-based MMA-co-BA graft copolymers resulted in an improved tensile strength and a higher Young's modulus. This research could provide not only a new avenue to utilize waste biomass for high-value applications, but also a reference for designing new materials for coatings or adhesives.

Keywords: lignin; macromolecular chain transfer agent; RAFT miniemulsion polymerization; thermal behavior; mechanical performance

\section{Introduction}

Acrylate resins, which are versatile copolymers produced basically from petroleum resources, play an important role in elastomer, coating, adhesive, and composite industries [1-4]. In the context of rising global warming and limited fossil fuel reserves, researchers in related fields have been making the utmost effort to search for regenerative resources for the preparation of acrylic resins with sustainability, a lower carbon footprint, and a relatively low cost [5-7]. Therefore, many reports have previously been published on the preparation of environmentally friendly acrylic polymers from a wide variety of sustainable resources [8], including terpene [9-11], tannins [12], lactone [13], lactic acid [14,15], chitosan [16], vegetable oils [17-20], cardanol [21-23], and lignin [24,25].

Lignin, industrially generated as a byproduct of paper and bio-refinery, is the second most abundant biomass on the Earth. Therefore, utilizing this sustainable resource can be cost-effective and can lead to much higher profits for these two industries, as well as producing a higher environmental value [26-28]. The active functional groups in lignin, such as methoxyl, carboxyl, and hydroxyl, offer a number of opportunities for synthesis of lignin-based green materials [29-31]. Lignin from cornstalk has been investigated 
for a number of years [32-35], and reports focus mainly on structure characterization of lignin [32,33], preparation of lignin-based functional materials [34], and composites based on modified lignin [35]. In addition, acrylamide can react with itself and other various monomers [36]. These homopolymers and copolymers have been found to have numerous applications [37], especially in the paper industry, in wastewater treatment, and as soil conditioners to improve soil texture.

In our previous study, the preparation and properties of lignin-grafted acrylic copolymers from lignocellulosic butanol residue via free radical polymerization were elucidated in some detail [24]. Some researchers have focused on the synthesis of renewable acrylic resins using controlled radical polymerization [38], atom transfer radical polymerization (ATRP) [39], and reversible addition-fragmentation transfer (RAFT) reactions [40].

As compared to conventional free radical methods, living radical polymerization can confer numerous benefits [41-43]. These involve the capability of controlling molecular weight and polydispersity and of synthesizing block copolymers, as well as materials of complex polymeric architectures not readily prepared using other techniques [44-47]. What distinguishes the RAFT process from other methods of living radical polymerization is that it can be carried out under various reaction conditions for a wide range of monomers [48-51]. The RAFT approach has been successfully used in the polymerization of acrylic monomers [52-55].

A survey of the literature shows that most of the bio-based acrylate resins to date have been designed and synthesized using free radical polymerization [24,56,57], ATRP [25,58], and RAFT polymerization [40] in organic media. To the best of our knowledge, no research has been reported on the preparation of (meth) acrylate resins utilizing a lignin-based copolymer as a macromolecular chain transfer agent by RAFT miniemulsion polymerization.

The chief goal of this study was to prepare lignin-based hybrid acrylate resins via RAFT miniemulsion polymerization. In this research, lignin xanthate was first synthesized and then reacted with acrylamide to produce a lignin-based polymeric RAFT agent. The chemical functionality of the lignin-graft-polyacrylamide (lignin-g-PAM) was also investigated. The methyl methacrylate copolymerized with butyl acrylate (MMA-co-BA) hybrid latex was synthesized using lignin-g-PAM as the chain transfer agent via RAFT miniemulsion polymerization, leading to graft copolymer lignin-g-PAM-b-(MMA-co-BA). The thermal transition of these lignin-based hybrid acrylic resins was determined through a differential scanning calorimeter (DSC), and the thermal degradation of these hybrid resins was also examined using the thermogravimetric analysis (TGA) technique. In addition, the mechanical performance of the lignin-based MMA-co-BA hybrid resin was also studied with a stress-strain testing machine.

\section{Materials and Methods}

\subsection{Materials}

The lignin used in this study was the residue that resulted from the production of butanol using cornstalks, and it was supplied by Bairui Bio-Polyos Co. Ltd. (Songyuan, China). Acrylamide (AM, 99\%) and potassium persulfate (KPS) were purchased from Beijing Biotopped Co. Ltd. and Aladdin Reagent Co. Ltd. (Shanghai, China), respectively. All other reagents, such as 2,2-azobisisobutyronitrile (AIBN), sodium dodecyl sulfonate (SDS), N,N-dimethylformamide (DMF), $n$-hexadecane (HD), butyl acrylate (BA), methyl methacrylate (MMA), ethyl acetate, and dichloromethane (DCM), were purchased from Sinopharm Chemical Reagent Co. Ltd (Shanghai, China).

\subsection{Synthesis of the Lignin-Based Polymeric RAFT Agent}

Lignin xanthate was synthesized beforehand using a one-pot reaction, as illustrated in Figure 1. Lignin xanthate (1.0 g, $1.14 \mathrm{mmol}$ xanthate group), AM (2.8 g, $38.00 \mathrm{mmol})$, and AIBN $(62.4 \mathrm{mg}, 0.38 \mathrm{mmol})$ were added to a $50 \mathrm{~mL}$ two-necked flask with a loading of $16 \mathrm{~mL}$ of DMF. Followed by purging with nitrogen $\left(\mathrm{N}_{2}\right)$ for $45 \mathrm{~min}$, the resulting 
solution was first heated to $70{ }^{\circ} \mathrm{C}$ under magnetic stirring and then maintained at the same reaction temperature for $24 \mathrm{~h}$. The precipitate was separated using filtration after the mixture was cooled to ambient temperature. Finally, the obtained copolymer ligningraft-polyacrylamide (lignin-g-PAM) was thoroughly purified using DCM and dried to a constant weight under a vacuum at $30^{\circ} \mathrm{C}$. The number average molecular weight gained in the experiment was about $6029 \mathrm{~g} / \mathrm{mol}$ (molecular weight distribution $=1.54$ ).

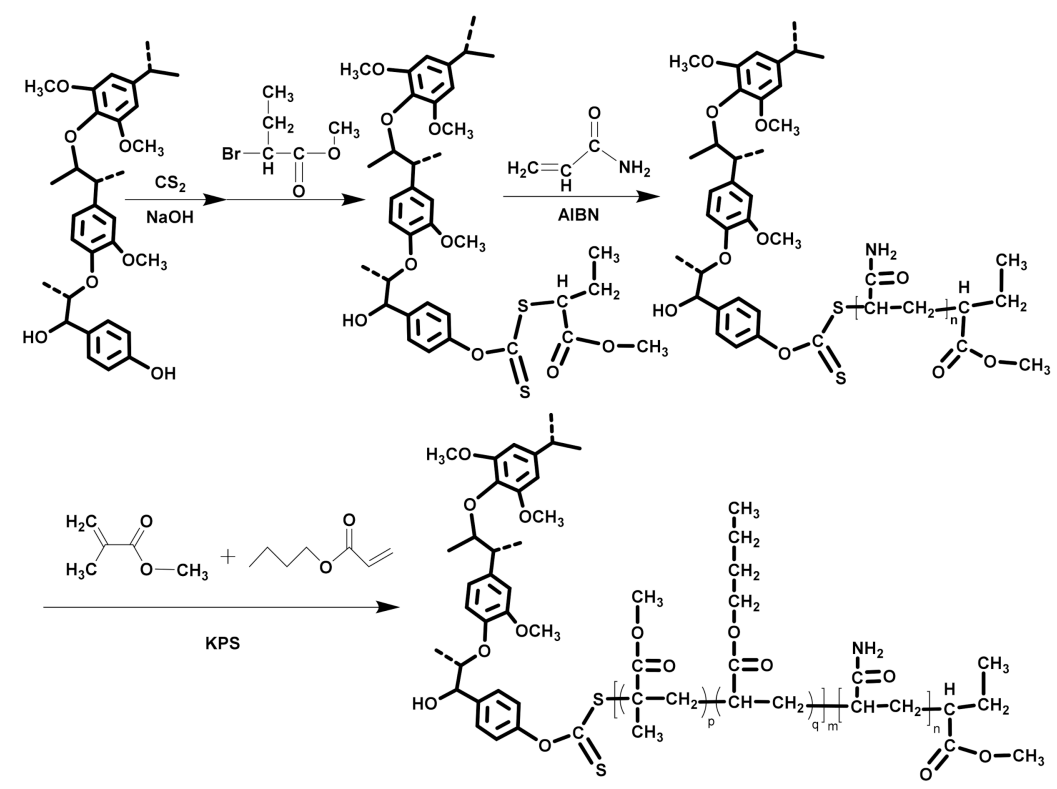

Figure 1. Schemes for the synthesis of lignin-graft-polyacrylamide (lignin-g-PAM) and methyl methacrylate copolymerized with butyl acrylate (lignin-based MMA-co-BA) hybrid resins.

\subsection{Synthesis of the Lignin-Based MMA-co-BA Hybrid Resins}

Using lignin-g-PAM as the chain transfer agent, a typical reaction for the preparation of the lignin-based MMA-co-BA hybrid resin was carried out as follows: SDS (0.25 g) and KPS (0.09 g) were dissolved in $60 \mathrm{~g}$ of tap water and mixed with lignin-g-PAM (20 wt $\%$ of total MMA and BA weights); HD (0.1 g) and $5.6 \mathrm{~g}$ MMA were mixed with $4.4 \mathrm{~g}$ BA. Then, the mixture was treated using ultrasonic irradiation in a bath of ice water for $12 \mathrm{~min}$. The resulting emulsion was immediately added to a $150 \mathrm{~mL}$ three-necked flask. After purging with $\mathrm{N}_{2}$ for $30 \mathrm{~min}$, the system was heated to $75^{\circ} \mathrm{C}$ and held constant for $6 \mathrm{~h}$. Subsequently, the reaction gel was filtered out after the polymerization system was cooled down to ambient temperature. The monomer conversion of the above-mentioned RAFT miniemulsion polymerization was about $86 \%$ (Table 1 ). The extraction procedure using ethyl acetate was performed to remove impurities from the obtained block copolymers for analysis of the chemical structure and properties. The preparation scheme and the molecular model of the lignin-based MMA-co-BA hybrid resins are shown in Figure 1.

Table 1. Reversible addition-fragmentation transfer (RAFT) polymerization conditions and main characteristics of pure MMA-co-BA and lignin-based hybrid acrylate latexes.

\begin{tabular}{ccccccc}
\hline $\begin{array}{c}\text { Lignin-g-PAM Dosage } \\
(\mathbf{w t} \%)\end{array}$ & $\begin{array}{c}\text { Temperature } \\
\left({ }^{\circ} \mathbf{C}\right)\end{array}$ & $\begin{array}{c}\text { Conversion } \\
\mathbf{( \% )}\end{array}$ & $\begin{array}{c}\text { Viscosity } \\
(\mathbf{m P a} \cdot \mathbf{s})\end{array}$ & $\begin{array}{c}\boldsymbol{M}_{\mathbf{n}} \\
(\mathbf{g} / \mathbf{m o l})\end{array}$ & $\boldsymbol{M}_{\mathbf{w}} / \mathbf{M}_{\mathbf{n}}$ & Gel Fraction (\%) \\
\hline 0 & 75 & 85.0 & 34.6 & 129,000 & 3.70 & 0.03 \\
20 & 75 & 86.1 & 36.6 & 638,000 & 2.84 & 0.02 \\
40 & 75 & 88.3 & 36.3 & 802,000 & 2.55 & 0.05 \\
60 & 75 & 87.5 & 28.3 & 446,000 & 2.25 & 0.11 \\
40 & 65 & 63.3 & 26.3 & 237,000 & 2.39 & 0.03 \\
40 & 85 & 89.3 & 26.5 & $1,007,000$ & 4.17 & 0.08 \\
\hline
\end{tabular}

* Measured by gravimetry. 


\subsection{Analytics}

\subsubsection{Attenuated Total Reflectance-Fourier Transform Infrared (ATR-FTIR)}

The molecular structure of graft copolymers synthesized in the above-mentioned experiment was investigated using Fourier transform infrared (FTIR) spectrometry. The absorption spectra were recorded through a FTIR spectrometer (Nicolet iS10 Thermo Fisher Corporation, Madison, WI, USA) coupled with an attenuated total reflectance (ATR) accessory by scanning between 4000 and $500 \mathrm{~cm}^{-1}$. Transmission spectra data were collected by averaging 16 scans at a $4 \mathrm{~cm}^{-1}$ resolution.

\subsection{2. ${ }^{1} \mathrm{H}$ Nuclear Magnetic Resonance $\left({ }^{1} \mathrm{H}\right.$ NMR)}

The ${ }^{1} \mathrm{H}$ NMR method was used to analyze the samples on an NMR apparatus (500 MHz, Bruker DRX500, Berlin, Germany). The spectra of the copolymers were obtained using tetramethylsilane as the internal reference at $25^{\circ} \mathrm{C}$ with the relaxation time of $1.0 \mathrm{~s}$; the employed solvent for the NMR test was dimethyl sulfoxide-d6 (DMSO-d6).

\subsubsection{Gel Permeation Chromatograph (GPC)}

The average molecular weights of the copolymers were tested on a gel permeation chromatograph (Malvern Viscotek, Malvern, UK) with the refractive index detector at $40^{\circ} \mathrm{C}$. The efficient eluent taken in this test was DMF, flowing at a speed of $1.0 \mathrm{~mL} / \mathrm{min}$. According to the experimental data, the average molecular weights were calculated using a method in which the molecular weight curve was calibrated with polystyrene standards. The concentration of the samples in DMF, filtered using microfilters with a pore diameter of $0.22 \mu \mathrm{m}$, was around $3.0 \mathrm{mg} / \mathrm{mL}$.

\subsubsection{Transmission Electron Microscopy (TEM)}

Transmission electron microscopy (TEM; JEM-1000, Tokyo, Japan) was used to characterize the particle morphology and the size of the samples. In preparation for the TEM specimen, the graft copolymer and pure MMA-co-BA polymer solutions were diluted using deionized water and placed dropwise onto a copper grid, followed by drying at room temperature for TEM analysis.

\subsubsection{Differential Scanning Calorimetry (DSC)}

The thermal behavior of the samples was investigated by the use of differential scanning calorimetry (Diamond DSC, Woodland, CA, USA). About $5 \mathrm{mg}$ of each specimen was loaded and then tested with $\mathrm{N}_{2}$ flowing at a rate of $45 \mathrm{~mL} / \mathrm{min}$. To remove any thermal history, each specimen was scanned twice at a speed of $20^{\circ} \mathrm{C} / \mathrm{min}$ between -55 and $150{ }^{\circ} \mathrm{C}$. Data collection was performed during the second scanning cycle.

\subsubsection{Thermogravimetric Analysis (TGA)}

The thermal decomposition of the lignin-based MMA-co-BA graft copolymers was studied via TGA (Netzsch STA409, Selb, Germany). For TGA analysis, a typical test was performed using around $10 \mathrm{mg}$ of the specimen under $\mathrm{N}_{2}$ between 30 and $700{ }^{\circ} \mathrm{C}$ at a speed of $10^{\circ} \mathrm{C} / \mathrm{min}$.

\subsubsection{Mechanical Performance}

Test specimens were prepared by emulsion casting (thickness $0.2 \mathrm{~mm}$ ) in an aluminum foil mold at $40{ }^{\circ} \mathrm{C}$ up to complete water evaporation. The dumbbell-shaped specimens were cut to $16.0 \mathrm{~mm} \times 4.0 \mathrm{~mm}$ before testing at room temperature. Under the same conditions, three counterparts for each sample were measured. The stress-strain tests were conducted at a speed of $50 \mathrm{~mm} / \mathrm{min}$ according to universal ISO 527-3. 


\section{Results and Discussion}

\subsection{Characterization of Lignin-g-PAM}

The poor solubility of lignin xanthate in water retards its direct utilization in RAFT miniemulsion polymerization. As shown in Figure 1, the lignin-g-PAM macromolecular chain transfer agent was synthesized in the RAFT polymerization of acrylamide with lignin xanthate used as a chain transfer agent. After purification, functional xanthate groups were still attached in lignin-g-PAM.

As displayed in the ATR-FTIR spectra of lignin and lignin xanthate, the peak located at $1511 \mathrm{~cm}^{-1}$ is assigned to the aromatic ring from lignin [33]. However, this peak was not observed in the lignin-g-PAM spectrum due to the low concentration of the benzene ring. Compared with lignin xanthate, the ATR-FTIR spectrum (Figure 2a) of lignin-g-PAM displays a sharp peak at $1650 \mathrm{~cm}^{-1}$, which is associated with a carbonyl bond of the amide group [36]. In contrast, a wide absorption peak ranging from 3200 to $3590 \mathrm{~cm}^{-1}$, related to some $-\mathrm{OH}$ residue from lignin xanthate, was separated after a grafting reaction. Therefore, two absorption peaks at 3337 and $3190 \mathrm{~cm}^{-1}$, related to the $\mathrm{N}-\mathrm{H}$ vibration and the $\mathrm{N}-\mathrm{H}$ stretching of amine groups [36], also appeared. As presented in Figure 2a, the spectrum of lignin-g-PAM was very similar to that of PAM, because a considerable amount of PAM had grafted from lignin xanthate. Moreover, the polymerization of acrylamide with lignin xanthate also resulted in solubility changing, and, thus, lignin-g-PAM dissolved readily in water, while lignin xanthate had nearly no water solubility.
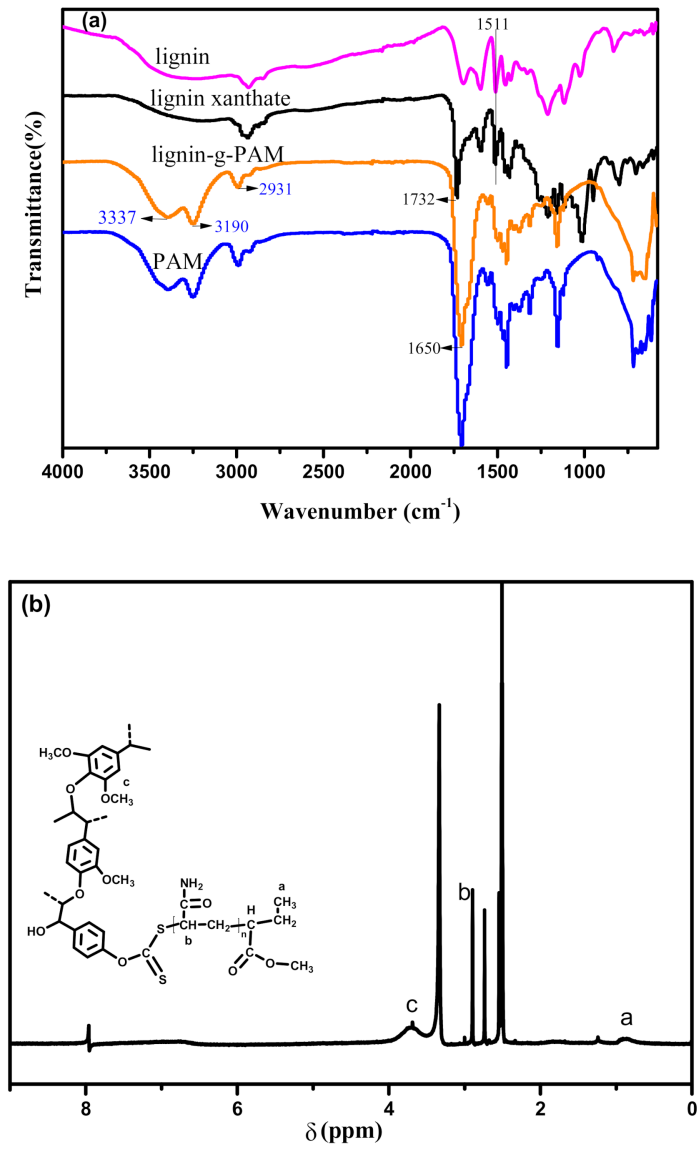

Figure 2. Attenuated total reflectance-Fourier transform (ATR-FTIR) spectra of lignin, lignin xanthate, lignin-g-PAM, and PAM (a), and ${ }^{1} \mathrm{H}$ NMR spectrum of lignin-g-PAM (b).

Two peaks appeared at $0.9 \mathrm{ppm}$ and $3.7 \mathrm{ppm}$, as shown in the ${ }^{1} \mathrm{H}$ NMR spectrum of lignin-g-PAM (Figure $2 b$ ), which are associated with the protons of the end $-\mathrm{CH}_{3}$ from the xanthates group and that of the methoxy group from lignin, respectively. 


\subsection{RAFT Miniemulsion Polymerization and Properties of the Lignin-Based MMA-co-BA Hybrid Resin}

To evaluate the efficacy of lignin-g-PAM in this article, RAFT miniemulsion polymerization of MMA and BA was investigated with different dosages of this macromolecular chain transfer agent. Then, we ran a group of polymerization reactions by simply varying the amount of lignin-g-PAM followed by changing the reaction temperature with the amount of lignin-g-PAM fixed at $40 \%$. The resultant polymer was named lignin-g-PAM-b(MMA-co-BA). The characteristics of the resulting latex prepared under various reaction conditions are summarized in Table 1. The gel fraction (GF) was determined as follows:

$$
\mathrm{GF}(\%)=W_{2} / W_{1} \times 100
$$

In this equation, $W_{1}$ is the total amount of the sample added to the lab flask, and $W_{2}$ is the amount of that extracted sample corresponding to the residuals (gel fraction).

As presented in Table 1, the RAFT polymerization reactions were carried out using acrylate monomers with lignin-g-PAM as the chain transfer agent at $75^{\circ} \mathrm{C}$ to achieve high conversions above $87 \%$, as determined by gravimetry. The polymerization rates were found to be much faster at a higher reaction temperature. Nearly $90 \%$ conversion was obtained at $85^{\circ} \mathrm{C}$ after $6 \mathrm{~h}$, while it took the same period of time for the same solution to reach as low as $63.3 \%$ conversion at $65^{\circ} \mathrm{C}$.

It was noted that the gel fraction was relatively low $(0.02-0.11 \%)$ under all experimental conditions, and the polymerization of latex was stable throughout the entire process. It is also worth noting that these lignin-based MMA-co-BA hybrid latexes achieved high stability, of which the apparent viscosity and particle size did not display a minor increase over several months. The latexes resulting from our technique were stabilized by incorporating blocks of the hydrophilic monomer, acrylamide, in support of previous proposed findings [59]. Herein, lignin-g-PAM, a surface-active macromolecular RAFT agent composed of a hydrophilic polyacrylamide block and a hydrophobic lignin molecular chain, also had a favorable effect on latex stability. The relative stability of the dispersions is consistent with the results of the other systems reported earlier [60,61].

As a typical case, the morphology of the lignin-based MMA-co-BA hybrid latex synthesized using $40 \%$ lignin-g-PAM was examined by TEM in comparison to that of the pure MMA-co-BA. The TEM micrographs of the particle size of pure MMA-co-BA and 40\% diluted lignin-g-PAM-b-(MMA-co-BA) latexes are shown in Figure 3a,b. As observed, the images of submicrometric particles are extremely similar for the two samples. The particle size of the latex prepared with $40 \%$ lignin-g-PAM (Figure 3a) was analyzed using ImageJ software and characterized by different particle diameters ranging approximately between 75 and $153 \mathrm{~nm}$, with the majority around $95-125 \mathrm{~nm}$. While the distribution of the particle size of pure MMA-co-BA latex existed between 62 and $151 \mathrm{~nm}$, the vast majority was around 75-105 nm (Figure $3 \mathrm{~b}$ ). Furthermore, the mean particle size and standard deviation for 40\% lignin-g-PAM-b-(MMA-co-BA) and pure MMA-co-BA were $108 \pm 15 \mathrm{~nm}$ and $89 \pm 12 \mathrm{~nm}$, respectively. The particle size distribution in this study is very similar to the previous results obtained using RAFT miniemulsion polymerization [62]. These results outlined above lead us to believe that the RAFT miniemulsion polymerization was carried out successfully. 


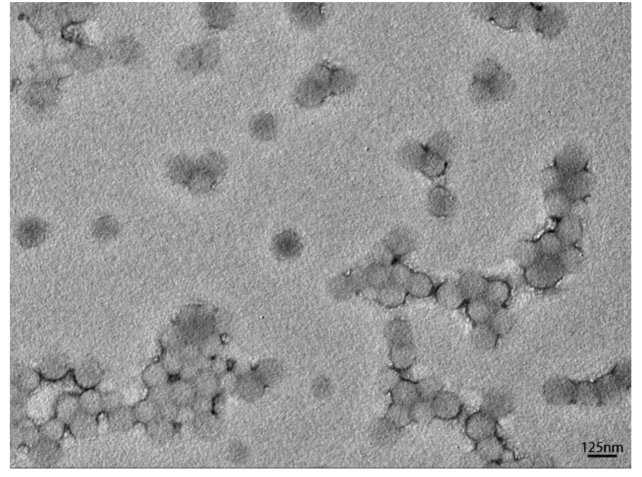

(a)

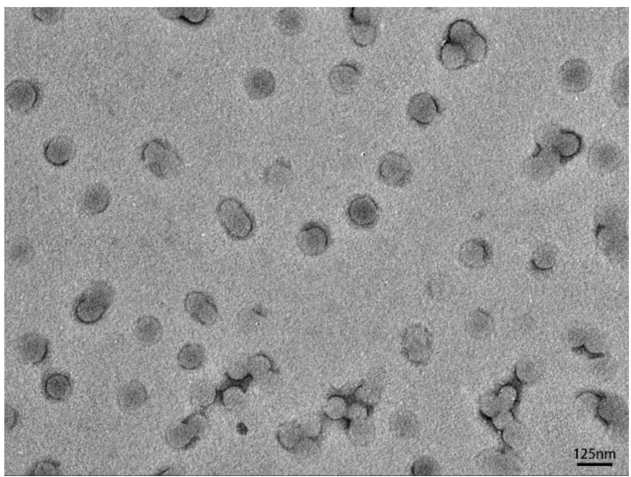

(b)

Figure 3. TEM images of the final latexes for lignin-based hybrid acrylate latex (a) and pure MMA-co-BA (b).

\subsection{Characteristics of the Chemical Structure of the Lignin-Based Hybrid Acrylate Resins}

The chemical structure of the lignin-based MMA-co-BA hybrid resin and the lignin-gPAM chain transfer agent, compared to a reference MMA-co-BA copolymer, was analyzed using ATR-FTIR. Figure 4 shows the spectra of the above-mentioned copolymers.

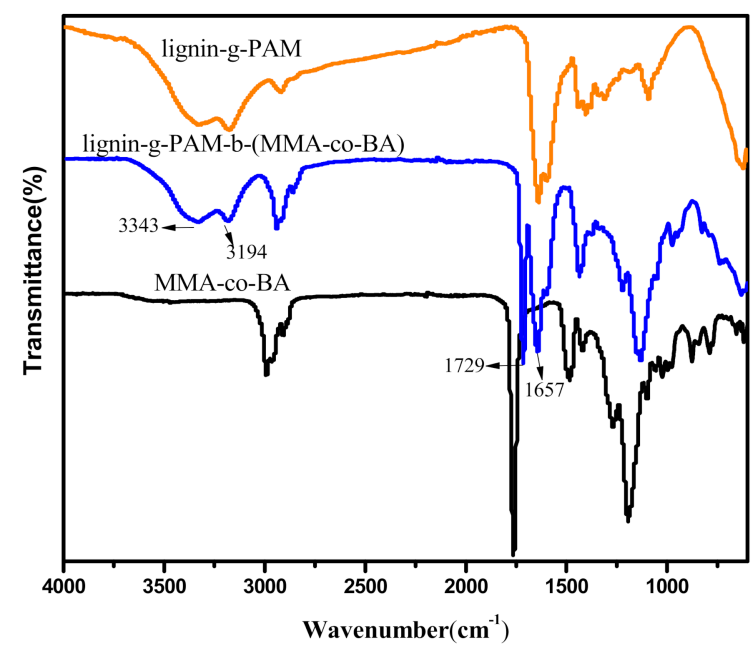

Figure 4. ATR-FTIR spectra of pure MMA-co-BA, lignin-grafted hybrid acrylate copolymer, and lignin-g-PAM.

The ATR-FTIR spectra of the lignin-based hybrid acrylic resin and lignin-g-PAM are extremely alike, but the vibration of the carbonyl group corresponding to $1729 \mathrm{~cm}^{-1}$ in the spectrum of the lignin-grafted MMA-co-BA resin confirms that the ester groups were incorporated into the lignin-g-PAM by RAFT miniemulsion polymerization. The strong absorption of peaks appeared at $3343 \mathrm{~cm}^{-1}$ and $3194 \mathrm{~cm}^{-1}$ in relation to the $-\mathrm{NH}_{2}$ stretching vibration of the unbonded amine group and that of the associated group, respectively. In addition, an absorption band at $1657 \mathrm{~cm}^{-1}$ associated with $\mathrm{C}=\mathrm{O}$ amide was also found, similar to previous literature reports [36]. The ${ }^{1} \mathrm{H}$ NMR spectrum of the lignin-based hybrid acrylic resin clearly showed a peak at $0.87 \mathrm{ppm}$ mainly corresponding to the protons on the end $-\mathrm{CH}_{3}$ of the alkyl chain for BA (Figure 5). 


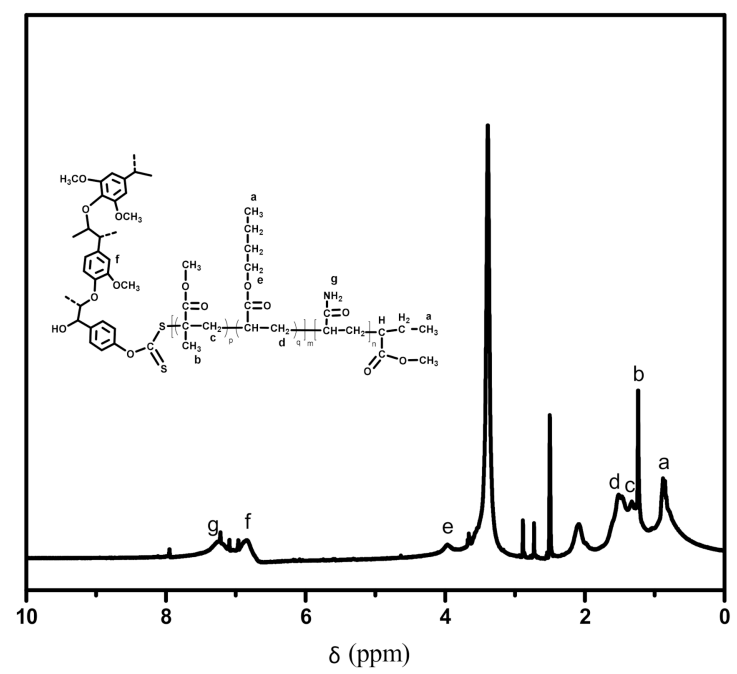

Figure 5. ${ }^{1} \mathrm{H}$ NMR spectrum of lignin-g-PAM-b-(MMA-co-BA).

\subsection{Thermal Behavior}

The glass transition temperature $\left(T_{\mathrm{g}}\right)$, manifesting the macromolecular chain's flexibility of the lignin-grafted MMA-co-BA copolymers and pure acrylic resin (MMA-co-BA), was characterized through DSC. Figure 6 displays the $T_{g}$ values of the pure MMA-co-BA copolymer and lignin-grafted hybrid acrylic resins. As expected, in this experiment, the $T_{\mathrm{g}}$ of the lignin-grafted hybrid acrylic resins was higher than that of the linear acrylic copolymer, in which the MMA-to-BA ratio was equal by mole. With the mass ratio of lignin-g-PAM to acrylic monomers increasing, the $T_{\mathrm{g}}$ of the lignin-grafted hybrid acrylic resin increased. Thus, the higher $T_{\mathrm{g}}$ followed the higher percentage of the lignin-based macromolecular RAFT agent consistently. The higher $T_{\mathrm{g}}$ of the lignin-grafted hybrid acrylic resins could be attributed to the incorporation of lignin-g-PAM. As presented in Figure 6, the glass transition temperatures of the lignin-grafted MMA-co-BA copolymers $(3.7,56.6$, and $\left.58.6^{\circ} \mathrm{C}\right)$ existed between that of lignin-g-PAM $\left(185.2{ }^{\circ} \mathrm{C}\right)$ and pure MMA-co-BA $\left(-1.3^{\circ} \mathrm{C}\right)$, which demonstrates that lignin-g-PAM-b-(MMA-co-BA) block copolymers synthesized through the RAFT miniemulsion polymerization. The shift in $T_{\mathrm{g}}$ is due to forming amounts of the homogeneous mixed phase [63]. The results should further underline the successful block-co-polymerization contributing to the low gel fraction $(0.02-0.11 \%)$ listed in Table 1.

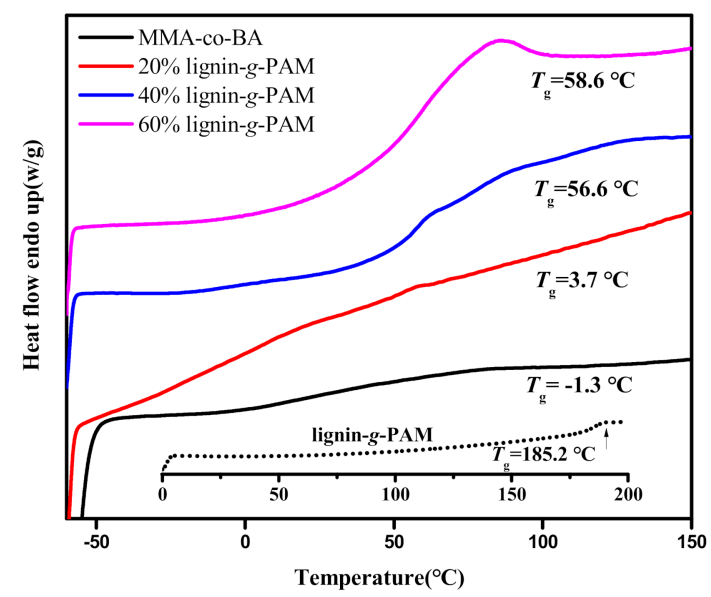

Figure 6. Differential scanning calorimetry (DSC) curves of lignin-g-PAM, pure MMA-co-BA, and lignin-grafted hybrid acrylic resins.

The thermal stability of the pure acrylic resin and bio-based acrylic resins comprising lignin-g-PAM and lignin was investigated using TGA under an $\mathrm{N}_{2}$ atmosphere. Figure 7 
shows these curves of TG and the resulting first derivatives (DTG, the rate of mass change as a function of temperature). The TGA results for $\mathrm{T}_{d} 5 \%, \mathrm{~T}_{d} 10 \%, \mathrm{~T}_{d}$ max, and carbon residue are summarized in Table 2.
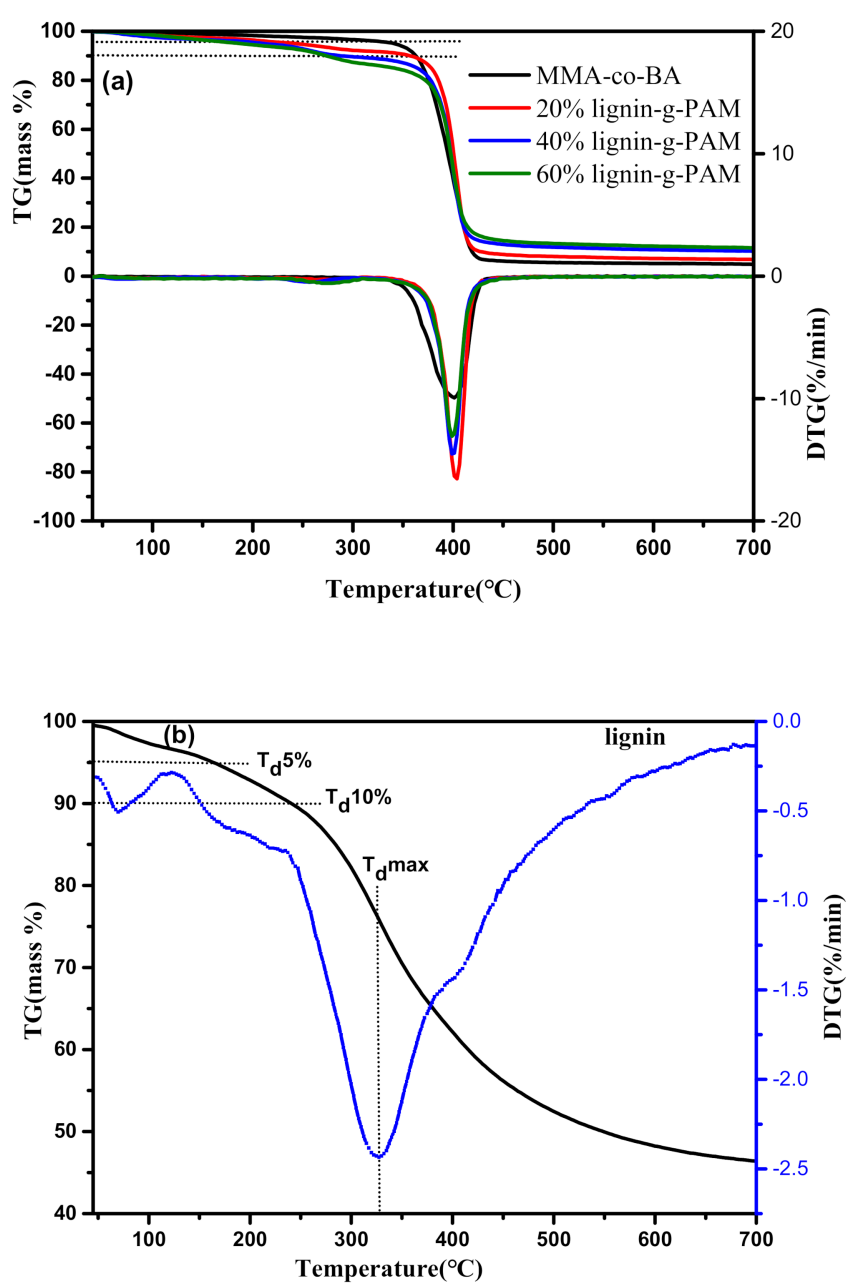

Figure 7. TG and DTG curves of the pure MMA-co-BA and lignin-based hybrid acrylic resins (a), and lignin (b).

Table 2. Thermogravimetric analysis results for $\mathrm{T}_{d} 5 \%, \mathrm{~T}_{\mathrm{d}} 10 \%, \mathrm{~T}_{\mathrm{d}}$ max, and carbon residue.

\begin{tabular}{ccccc}
\hline Sample & $\begin{array}{c}\mathbf{T}_{\mathbf{d}} \mathbf{5} \% \\
\mathbf{(} \mathbf{C})\end{array}$ & $\begin{array}{c}\mathbf{T}_{\mathbf{d}} \mathbf{1 0} \% \\
\left({ }^{\circ} \mathbf{C}\right)\end{array}$ & $\begin{array}{c}\mathbf{T}_{\mathbf{d}} \mathbf{m a x} \\
\left({ }^{\circ} \mathbf{C}\right)\end{array}$ & $\begin{array}{c}\text { Carbon Residue } \\
\mathbf{( \% )}\end{array}$ \\
\hline MMA-co-BA & 341 & 362 & 410 & 3.9 \\
20\% lignin-g-PAM & 242 & 358 & 403 & 9.8 \\
40\% lignin-g-PAM & 210 & 288 & 393 & 16.3 \\
60\% lignin-g-PAM & 188 & 273 & 390 & 18.0 \\
lignin & 163 & 240 & 327 & 44 \\
\hline
\end{tabular}

The results show that the lignin-grafted MMA-co-BA resin started losing weight at lower temperatures in comparison to the pure acrylic copolymer. Furthermore, with the percentage of lignin-g-PAM increasing, the maximum decomposition temperatures of lignin-based hybrid acrylic resins decreased slightly from 410 to $390^{\circ} \mathrm{C}$. The above data demonstrate lower thermal stability of these hybrid acrylic resins than that of the linear MMA-co-BA copolymer, which could be mainly due to the microscopic phase separation resulting from the lignin with a lower molecular weight and, hence, a lower curing density of hybrid acrylic graft polymers [64]. 
As listed in Table 2, the $T_{d} 5 \%, T_{d} 10 \%$, and $T_{d}$ max for lignin were lower than those of the MMA-co-BA and lignin-g-PAM-b-(MMA-co-BA) block copolymers. It was also observed that the $\mathrm{T}_{\mathrm{d}} 5 \%, \mathrm{~T}_{\mathrm{d}} 10 \%$, and $\mathrm{T}_{\mathrm{d}}$ max for pure MMA-co-BA were higher than those for all obtained lignin-g-PAM-b-(MMA-co-BA) block copolymers. The results partly stem from the lignin incorporated in these block copolymers.

In addition, the lignin used in this research consisted of hemicellulose, cellulose, and other components with lower molecular weight; the synthesized lignin-grafted hybrid acrylic resin could also possibly have contained some hemicellulose. Hemicellulose usually has poorer thermostability than lignin does; therefore, the lignin-based MMA-co-BA resins decomposed below a comparatively lower temperature $\left(350{ }^{\circ} \mathrm{C}\right)$, partly because of the decomposition of hemicellulose incorporated into it [65]. Like other lignin-based polymers [64,65], these lignin-grafted hybrid acrylic resins decomposed with multiple complicated reactions occurring simultaneously. The above hybrid acrylic copolymers can also be depolymerized to $\mathrm{CO}_{2}, \mathrm{CO}, \mathrm{H}_{2} \mathrm{O}$, and monomers. The final carbon residue (CR) of the three lignin-based acrylic copolymers was $9.8-18.0 \%$ at $700{ }^{\circ} \mathrm{C}$, higher than that of linear acrylic copolymer (CR 3.9\%), which mainly resulted from lignin being incorporated into lignin-g-PAM-b-(MMA-co-BA) block copolymers.

\subsection{Mechanical Property}

Regarding the lignin-grafted MMA-co-BA hybrid resin, synthesized with $60 \%$ lignin-gPAM, the resulting sample was very brittle at room temperature. The mechanical properties of the pure acrylic copolymer and lignin-grafted hybrid acrylic resins that were synthesized at two different percentages of lignin-g-PAM (20 and $40 \mathrm{wt} \%$ ) were tested on a CMT4000 instrument.

The tensile strength was obtained as the maximum applied stress at failure, and the Young's modulus for the same samples was calculated from the slope of the stress-strain diagram. These recorded results are displayed in Table 3 and Figure 8. The data collected show that the mechanical properties (except failure strain, maximum load, Young's modulus, and tensile strength) of the hybrid acrylate resins significantly increased as a higher percentage of lignin-g-PAM in lignin-based MMA-co-BA copolymers was used. As observed, a low failure strain in 40\% lignin-g-PAM-b-(MMA-co-BA) may result in a poor deformation capacity and ductility of films at a higher ratio of the lignin-based macromolecular RAFT agent. One reason for this could be related to the more star-shaped architecture restricting chain mobility [25]. However, this hybrid acrylic resin prepared by RAFT polymerization using up to $40 \mathrm{wt} \%$ of lignin-g-PAM as the chain transfer agent showed a better Young's modulus and tensile strength when compared to that of the linear MMA-co-BA. This suggests a great untapped potential for the manufacturing of tunable and environmentally friendly coatings or adhesives as a type of bio-renewable material to partially substitute fossil-based polymers.

Table 3. Tensile properties of pure acrylic copolymer and lignin-grafted hybrid acrylic resins.

\begin{tabular}{ccccc}
\hline $\begin{array}{c}\text { Dose of Lignin-g-PAM } \\
(\mathbf{w t} \%)\end{array}$ & $\begin{array}{c}\text { Failure Strain } \\
\mathbf{( \% )}\end{array}$ & $\begin{array}{c}\text { Tensile Strength } \\
\mathbf{( M P a )}\end{array}$ & $\begin{array}{c}\text { Maximum Load } \\
\mathbf{( M P a )}\end{array}$ & $\begin{array}{c}\text { Young's Modulus } \\
\mathbf{( M P a )}\end{array}$ \\
\hline 0 & 1216.50 & 2.60 & 2.36 & 0.27 \\
20 & 863.96 & 6.56 & 8.90 & 17.03 \\
40 & 419.62 & 8.53 & 24.01 & 198.78 \\
\hline
\end{tabular}




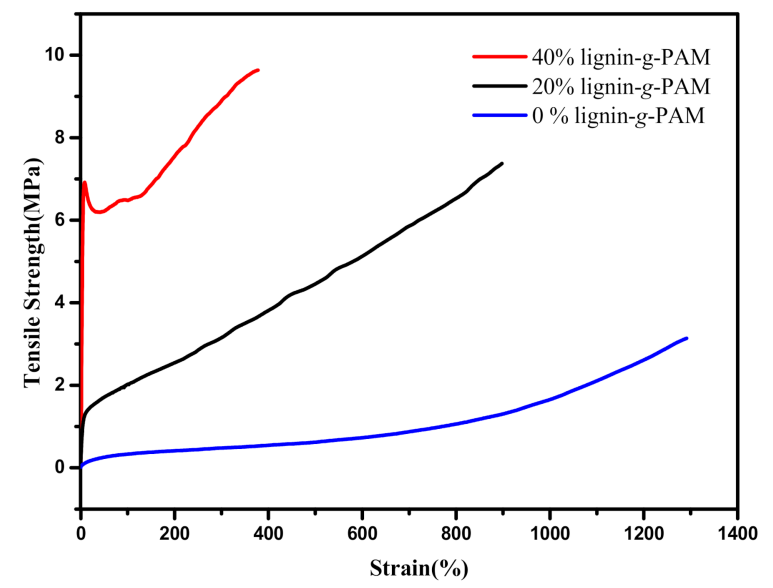

Figure 8. Strength-strain behaviors versus \% of lignin-g-PAM for synthesis of lignin-grafted hybrid acrylic resins.

\section{Conclusions}

The hybrid acrylic latexes incorporating a surface-active lignin-based macromolecular chain transfer agent were, without fail, prepared via RAFT miniemulsion polymerization. The ${ }^{1} \mathrm{H}$ NMR spectra, as well as the ATR-FTIR spectra, showed the attachment of acrylic molecular chains on the lignin. The $T_{\mathrm{g}}$ of lignin-based acrylic graft polymers was discovered to be higher than that of the pure acrylic copolymer in this experiment, of which the MMA-to-BA ratio was equal by mole. The TGA results revealed that the thermal stability of the acrylic hybrid resins was lower than that of the linear copolymer, which could have been caused by the microscopic phase separation of lignin-based acrylic graft polymers, partly due to the incorporation of lignin. However, these lignin-g-PAM-b(MMA-co-BA) resins strongly demonstrated a better Young's modulus and tensile strength as a result of the incorporated lignin when compared with the pure MMA-co-BA copolymer. The results obtained suggest that the lignin-based hybrid acrylic resins have good potential in the manufacturing of tunable bio-based materials as a partial substitute for petroleum-based copolymers.

Author Contributions: Conceptualization, Y.X., C.W., and F.C.; investigation, Y.X., N.L., and G.W.; writing - original draft preparation, Y.X. and G.W.; writing—review and editing, Y.X., N.L., and C.W.; supervision, C.W. and F.C. All authors have read and agreed to the published version of the manuscript.

Funding: The authors are grateful to the National Natural Science Foundation of China (31770604, 31890774) for the financial support.

Data Availability Statement: The data presented in this study are available upon request from the corresponding author.

Conflicts of Interest: The authors declare no conflict of interest.

\section{References}

1. Riess, G.; Schlienger, M.; Marti, S. New morphologies in rubber-modified polymers. J. Polym. Sci. Part B Polym. Phys. 1980, 17, 355-374. [CrossRef]

2. Tong, J.D.; Jerome, R. Synthesis of poly(methyl methacrylate)-b-poly(n-butyl acrylate)-b-poly(methyl methacrylate) triblocks and their potential as thermoplastic elastomers. Polymer 2000, 41, 2499-2510. [CrossRef]

3. Czech, Z. Crosslinking of pressure sensitive adhesive based on water-borne acrylate. Polym. Int. 2003, 52, 347-357. [CrossRef]

4. Kaelble, D.H. Peel adhesion: Influence of surface energies and adhesive rheology. J. Adhesion. 1969, 1, 102-123. [CrossRef]

5. Galià, M.; de Espinosa, L.M.; Ronda, J.C.; Lligadas, G.; Cádiz, V. Vegetable oil-based thermosetting polymers. Eur. J. Lipid Sci. Technol. 2010, 112, 87-96. [CrossRef]

6. Lu, Y.-S.; Larock, R.C. New hybrid latexes from a soybean oil-based waterborne polyurethane and acrylics via emulsion polymerization. Biomacromolecules 2007, 8, 3108-3114. [CrossRef] 
7. Åkesson, D.; Skrifvars, M.; Walkenström, P. Preparation of thermoset composites from natural fibres and acrylate modified soybean oil resins. J. Appl. Polym. Sci. 2009, 114, 2502-2508. [CrossRef]

8. Veith, C.; Diot-Néant, F.; Miller, S.A.; Allais, F. Synthesis and polymerization of bio-based acrylates: A review. Polym. Chem. 2020, 11, 7452-7470. [CrossRef]

9. Ando, S.; Someya, Y.; Takahashi, T.; Shibata, M. Thermal and mechanical properties of photocured organic-inorganic hybrid nanocomposites of terpene-based acrylate resin and methacrylate-substituted polysilsesquioxane. J. Appl. Polym. Sci. 2010, 115, 3326-3331. [CrossRef]

10. Winnacker, M.; Rieger, B. Recent progress in sustainable polymers obtained from cyclic terpenes: Synthesis, properties, and application potential. ChemSusChem 2015, 8, 2455-2471. [CrossRef] [PubMed]

11. Sainz, M.F.; Souto, J.A.; Regentova, D.; Johansson, M.K.G.; Timhagen, S.T.; Irvine, D.J.; Buijsen, P.; Koning, C.E.; Stockman, R.A.; Howdle, S.M. A facile and green route to terpene derived acrylate and methacrylate monomers and simple free radical polymerisation to yield new renewable polymers and coatings. Polym. Chem. 2016, 7, 2882-2887. [CrossRef]

12. Jahanshahi, S.; Pizzi, A.; Abdulkhani, A.; Shakeri, A. Analysis and testing of bisphenol A-free bio-based tannin epoxy-acrylic adhesives. Polymers 2016, 8, 143. [CrossRef]

13. Bensabeh, N.; Moreno, A.; Roig, A.; Monaghan, O.R.; Ronda, J.C.; Cadiz, V.; Galia, M.; Howdle, S.M.; Lligadas, G.; Percec, V. Polyacrylates derived from biobased ethyl lactate solvent via SET-LRP. Biomacromolecules 2019, 20, 2135-2147. [CrossRef]

14. Bensabeh, N.; Moreno, A.; Roig, A.; Rahimzadeh, M.; Rahimi, K.; Ronda, J.C.; Cádiz, V.; Galià, M.; Percec, V.; RodriguezEmmenegger, C.; et al. Photoinduced upgrading of lactic acid-based solvents to block copolymer surfactants. ACS Sustain. Chem. Eng. 2020, 8, 1276-1284. [CrossRef]

15. Purushothaman, M.; Krishnan, P.S.G.; Nayak, S.K. Poly(alkyl lactate acrylate)s having tunable hydrophilicity. J. Appl. Polym. Sci. 2014, 131, 40962. [CrossRef]

16. Anbinder, P.; Macchi, C.; Amalvy, J.; Somoza, A. Chitosan-graft-poly(n-butyl acrylate) copolymer: Synthesis and characterization of a natural/synthetic hybrid material. Carbohyd. Polym. 2016, 145, 86-94. [CrossRef]

17. Cho, H.-G.; Park, S.-Y.; Jegal, J.; Song, B.-K.; Kim, H.-J. Preparation and characterization of acrylic polymers based on a novel acrylic monomer produced from vegetable oil. J. Appl. Polym. Sci. 2010, 116, 736-742. [CrossRef]

18. De Espinosa, L.M.; Ronda, J.C.; Galià, M.; Cádiz, V. A new route to acrylate oils: Crosslinking and properties of acrylate triglycerides from high oleic sunflower oil. J. Polym. Sci. Part A: Polym. Chem. 2009, 47, 1159-1167. [CrossRef]

19. Rengasamy, S.; Mannari, V. Development of soy-based UV-curable acrylate oligomers and study of their film properties. Prog. Org. Coat. 2013, 76, 78-85. [CrossRef]

20. Garrison, T.F.; Murawski, A.; Quirino, R.L. Bio-based polymers with potential for biodegradability. Polymers 2016, 8, 262. [CrossRef]

21. Liu, R.; Zhang, X.-P.; Zhu, J.-J.; Liu, X.-Y.; Wang, Z.; Yan, J.-L. UV-curable coatings from multiarmed cardanol-based acrylate oligomers. ACS Sustain. Chem. Eng. 2015, 3, 1313-1320. [CrossRef]

22. Hu, Y.; Shang, Q.-Q.; Tang, J.-J.; Wang, C.-N.; Zhang, F.; Jia, P.-Y.; Feng, G.-D.; Wu, Q.; Liu, C.-G.; Hu, L.-H.; et al. Use of cardanol-based acrylate as reactive diluent in UV-curable castor oil-based polyurethane acrylate resins. Ind. Crop. Prod. 2018, 117, 295-302. [CrossRef]

23. Ladmiral, V.; Jeannin, R.; Fernandes Lizarazu, K.; Lai-Kee-Him, J.; Bron, P.; Lacroix-Desmazes, P.; Caillol, S. Aromatic biobased polymer latex from cardanol. Eur. Polym. J. 2017, 93, 785-794. [CrossRef]

24. Liu, X.-H.; Wang, J.-F.; Li, S.-H.; Zhuang, X.-W.; Xu, Y.-Z.; Wang, C.-P.; Chu, F.-X. Preparation and properties of UV-absorbent lignin graft copolymer films from lignocellulosic butanol residue. Ind. Crop. Prod. 2014, 52, 633-641. [CrossRef]

25. Yu, J.; Wang, J.-F.; Wang, C.-P.; Liu, Y.-P.; Xu, Y.-Z.; Tang, C.-B.; Chu, F.-X. UV-absorbent lignin-based multi-arm star thermoplastic elastomers. Macromol. Rapid Comm. 2015, 36, 398-404. [CrossRef]

26. Bajwa, D.S.; Pourhashem, G.; Ullah, A.H.; Bajwa, S.G. A concise review of current lignin production, applications, products and their environmental impact. Ind. Crop. Prod. 2019, 139, 111526. [CrossRef]

27. Jiang, X.; Abbati de Assis, C.; Kollman, M.; Sun, R.-K.; Jameel, H.; Chang, H.-M.; Gonzalez, R. Lignin fractionation from laboratory to commercialization: Chemistry, scalability and techno-economic analysis. Green Chem. 2020, 22, 7448-7459. [CrossRef]

28. Sun, Z.; Fridrich, B.; de Santi, A.; Elangovan, S.; Barta, K. Bright side of lignin depolymerization: Toward new platform chemicals. Chem. Rev. 2018, 118, 614-678. [CrossRef]

29. Sun, D.; Wang, B.; Wang, H.-M.; Li, M.-F.; Shi, Q.; Zheng, L.; Wang, S.-F.; Liu, S.-J.; Sun, R.-C. Structural elucidation of tobacco stalk lignin isolated by different integrated processes. Ind. Crop. Prod. 2019, 140, 111631. [CrossRef]

30. Iravani, S.; Varma, R.S. Greener synthesis of lignin nanoparticles and their applications. Green Chem. 2020, 22, 612-636. [CrossRef]

31. Li, R.J.-X.; Gutierrez, J.; Chung, Y.-L.; Frank, C.W.; Billington, S.L.; Sattely, E.S. A lignin-epoxy resin derived from biomass as an alternative to formaldehyde-based wood adhesives. Green Chem. 2018, 20, 1459-1466. [CrossRef]

32. Bonini, C.; D'Auria, M.; Di Maggio, P.; Ferri, R. Characterization and degradation of lignin from steam explosion of pine and corn stalk of lignin: The role of superoxide ion and ozone. Ind. Crop. Prod. 2008, 27, 182-188. [CrossRef]

33. Yang, Q.; Shi, J.; Lin, L.; Zhuang, J.; Pang, C.; Xie, T.; Liu, Y. Structural characterization of lignin in the process of cooking of cornstalk with solid alkali and active oxygen. J. Agric. Food Chem. 2012, 60, 4656-4661. [CrossRef] [PubMed]

34. Zhu, S.; Chen, K.; Xu, J.; Li, J.; Mo, L. Bio-based polyurethane foam preparation employing lignin from corn stalk enzymatic hydrolysis residues. RSC Adv. 2018, 8, 15754-15761. [CrossRef] 
35. Wang, S.; Yu, Y.; Di, M. Green modification of corn stalk lignin and preparation of environmentally friendly lignin-based wood adhesive. Polymers 2018, 10, 631. [CrossRef]

36. Suckeveriene, R.Y.; Rahman, R.; Shtein, I.; Kharlamova, N.; Narkis, M. Synthesis of styrene-acrylamide copolymer by surfactantfree sonicated dynamic interfacial polymerization. Polym. Adv. Technol. 2012, 23, 1536-1542. [CrossRef]

37. Friedman, M. Chemistry, biochemistry, and safety of acrylamide. A review. J. Agric. Food Chem. 2003, 51, 4504-4526. [CrossRef]

38. Satoh, K. Controlled/living polymerization of renewable vinyl monomers into bio-based polymers. Polym. J. 2015, 47, 527-536. [CrossRef]

39. Anand, V.; Agarwal, S.; Greiner, A.; Choudhary, V. Synthesis of methyl methacrylate andN-aryl itaconimide block copolymersvia atom-transfer radical polymerization. Polym. Int. 2005, 54, 823-828. [CrossRef]

40. Satoh, K.; Lee, D.H.; Nagai, K.; Kamigaito, M. Precision synthesis of bio-based acrylic thermoplastic elastomer by RAFT polymerization of itaconic acid derivatives. Macromol. Rapid Comm. 2014, 35, 161-167. [CrossRef] [PubMed]

41. Colombani, D. Chain-growth control in free radical polymerization. Prog. Polym. Sci. 1997, 22, 1649-1720. [CrossRef]

42. Matyjaszewski, K.; Xia, J.-H. Atom transfer radical polymerization. Chem. Rev. 2001, 101, 2921-2990. [CrossRef]

43. Chiefari, J.; Chong, Y.K.B.; Ercole, F.; Krstina, J.; Jeffery, J.; Le, T.P.T.; Mayadunne, R.T.A.; Meijs, G.F.; Moad, C.L.; Moad, G.; et al. Living free-radical polymerization by reversible addition-fragmentation chain transfer: The RAFT process. Macromolecules 1998, 31, 5559-5562. [CrossRef]

44. Matyjaszewski, K.; Tsarevsky, N.V. Macromolecular engineering by atom transfer radical polymerization. J. Am. Chem. Soc. 2014, 136, 6513-6533. [CrossRef] [PubMed]

45. Chong, B.Y.K.; Le, T.P.T.; Moad, G.; Rizzardo, E.; Thang, S.H. A more versatile route to block copolymers and other polymers of complex architecture by living radical polymerization: The RAFT process. Macromolecules 1999, 32, 2071-2074. [CrossRef]

46. Tong, J.D.; Moineau, G.; Leclere, P.; Bredas, J.L.; Lazzaroni, R.; Jerome, R. Synthesis, morphology, and mechanical properties of poly(methyl methacrylate)-b-poly(n-butyl acrylate)-b-poly(methyl methacrylate) triblocks. ligated anionic polymerization vs. atom transfer radical polymerization. Macromolecules 2000, 33, 470-479. [CrossRef]

47. Shipp, D.A.; Wang, J.-L.; Matyjaszewski, K. Synthesis of acrylate and methacrylate block copolymers using atom transfer radical polymerization. Macromolecules 1998, 31, 8005-8008. [CrossRef]

48. Moad, G.; Rizzardo, E.; Thang, S.H. Living radical polymerization by the RAFT process-A third update. Aust. J. Chem. 2012, 65, 985-1076. [CrossRef]

49. Mayadunne, R.T.A.; Rizzardo, E.; Chiefari, J.; Chong, Y.K.; Moad, G.; Thang, S.H. Living radical polymerization with reversible addition-fragmentation chain transfer (RAFT polymerization) using dithiocarbamates as chain transfer agents. Macromolecules 1999, 32, 6977-6980. [CrossRef]

50. Lowe, A.B.; McCormick, C.L. Reversible addition-fragmentation chain transfer (RAFT) radical polymerization and the synthesis of water-soluble (co)polymers under homogeneous conditions in organic and aqueous media. Prog. Polym. Sci. 2007, 32, 283-351. [CrossRef]

51. Boyer, C.; Bulmus, V.; Davis, T.P.; Ladmiral, V.; Liu, J.; Perrier, S.B. Bioapplications of RAFT polymerization. Chem. Rev. 2009, 109, 5402-5436. [CrossRef] [PubMed]

52. Moad, G.; Chong, Y.K.; Postma, A.; Rizzardo, E.; Thang, S.H. Advances in RAFT polymerization: The synthesis of polymers with defined end-groups. Polymer 2005, 46, 8458-8468. [CrossRef]

53. Perrier, S.B.; Barner-Kowollik, C.; Quinn, J.F.; Vana, P.; Davis, T.P. Origin of inhibition effects in the reversible addition fragmentation chain transfer (RAFT) polymerization of methyl acrylate. Macromolecules 2002, 35, 8300-8306. [CrossRef]

54. Nguyen, M.N.; Bressy, C.; Margaillan, A. Synthesis of novel random and block copolymers of tert-butyldimethylsilyl methacrylate and methyl methacrylate by RAFT polymerization. Polymer 2009, 50, 3086-3094. [CrossRef]

55. Jiang, Y.-J.; Li, L.; Liu, J.-P.; Wang, R.; Wang, H.-S.; Tian, Q.; Li, X.-Y. Hydrophobic films of acrylic emulsion by incorporation of fluorine-based copolymer prepared through the RAFT emulsion copolymerization. J. Fluorine Chem. 2016, 183, 82-91. [CrossRef]

56. Fu, L.-Y.; Yang, L.-T.; Dai, C.-L.; Zhao, C.-S.; Ma, L.-J. Thermal and mechanical properties of acrylated expoxidized-soybean oil-based thermosets. J. Appl. Polym. Sci. 2010, 117, 2220-2225. [CrossRef]

57. De Oliveira, H.F.; Felisberti, M.I. Amphiphilic copolymers of sucrose methacrylate and acrylic monomers: Bio-based materials from renewable resource. Carbohyd. Polym. 2013, 94, 317-322. [CrossRef]

58. Wang, J.-F.; Yao, K.-J.; Korich, A.L.; Li, S.-G.; Ma, S.-G.; Ploehn, H.J.; Iovine, P.M.; Wang, C.-P.; Chu, F.-X.; Tang, C.-B. Combining renewable gum rosin and lignin: Towards hydrophobic polymer composites by controlled polymerization. J. Polym. Sci. Part A Polym. Chem. 2011, 49, 3728-3738. [CrossRef]

59. Ferguson, C.J.; Hughes, R.J.; Nguyen, D.; Pham, B.T.T.; Gilbert, R.G.; Serelis, A.K.; Such, C.H.; Hawkett, B.S. Ab initio emulsion polymerization by RAFT-controlled self-assembly. Macromolecules 2005, 38, 2191-2204. [CrossRef]

60. Rieger, J.; Osterwinter, G.; Bui, C.; Stoffelbach, F.O.; Charleux, B. Surfactant-free controlled/living radical emulsion (co)polymerization of $n$-butyl acrylate and methyl methacrylate via RAFT using amphiphilic poly(ethylene oxide)-based trithiocarbonate chain transfer agents. Macromolecules 2009, 42, 5518-5525. [CrossRef]

61. Vosloo, J.J.; De Wet-Roos, D.; Tonge, M.P.; Sanderson, R.D. Controlled free radical polymerization in water-borne dispersion using reversible addition-fragmentation chain transfer. Macromolecules 2002, 35, 4894-4902. [CrossRef]

62. Lansalot, M.; Davis, T.P.; Heuts, J.P.A. RAFT miniemulsion polymerization: Influence of the structure of the RAFT agent. Macromolecules 2002, 35, 7582-7591. [CrossRef] 
63. Morese-Seguela, B.; St-Jacques, M.; Renaud, J.M.; Prod'Homme, J. Microphase separation in low molecular weight styreneisoprene diblock copolymers studied by DSC and 13 C NMR. Macromolecules 1980, 13, 100-106. [CrossRef]

64. Xu, Y.-Z.; Yuan, L.; Wang, Z.-K.; Wilbon, P.A.; Wang, C.-P.; Chu, F.-X.; Tang, C.-B. Lignin and soy oil-derived polymeric biocomposites by "grafting from" RAFT polymerization. Green Chem. 2016, 18, 4974-4981. [CrossRef]

65. Ferdosian, F.; Yuan, Z.-S.; Anderson, M.; Xu, C.-B. Synthesis and characterization of hydrolysis lignin-based epoxy resins. Ind. Crop. Prod. 2016, 91, 295-301. [CrossRef] 